the inhibitory control of feeding. Clearly, the present data are too gross for any strong arguments concerning the precise level of action of the observed effects.

Still, regardless of the ambiguities in the possible interpretation of these data, several noteworthy empirical facts were uncovered. First, pretreatment of rats with 2-DG prior to administration of stomach loads of glucose- ${ }^{-14} \mathrm{C}$ markedly modified the distribution of label within the body while reducing the satiating effect of glucose. These techniques, in combination with more refined analytical tools, may shed considerable light on the locus and nature of metabolic control of feeding behavior.

\section{REFERENCES}

Booth, D. A. Satiety and behavioral caloric compensation following intragastric glucose loads in the rat. Journal of
Comparative \& Physiological Psychology, 1972, 7 2412-432. Likuski, H. J., Debons, A. F., \& Cloutier, R. J. Inhibition of gold-thioglucose-induced hypothalamic obesity by glucose analogues. American Journal of Physiology, 1967, 212, 669-676.

Mayer, J. Regulation of energy intake and body weight: the glucostatic theory and lipostatic hypothesis. Annals of the New York Academy of Sciences, 1955, 63, 15-43.

Panksepp, J. Is satiety mediated by the ventromedial hypothalamus? Physiology \& Behavior, 1971a, 7, 381-384.

Panksepp, J. A re-examination of the role of the ventromedial hypothalamus in feeding behavior. Physiology \& Behavior, $1971 \mathrm{~b}, 7,385-394$.

Panksepp, J. Hypothalamic radioactivity after intragastric glucose- ${ }^{14} \mathrm{C}$ in rats. American Journal of Physiology, 1972, 223, 396-401:

Panksepp, J., \& Nance, D. M. Insulin, glucose and hypothalamic regulation of feeding. Physiology \& Behavior, 1972, 9, 447-451.

(Received for publication January 10, 1974.)

Bulletin of the Psychonomic Society

1974, Vol. 3 (5A), 327-329

\title{
Children's paired-associate learning: Response and associative learning as a function of similarity
}

\author{
ROBERT L. SOLSO \\ Loyola University of Chicago, Chicago, Illinois 60626 \\ JOHN H. MUELLER \\ University of Missouri, Columbia, Missouri 65201 \\ ROSARIO C. PESCE and GEORGE WEISS \\ Loyola University of Chicago, Chicago, Illinois 60626
}

\begin{abstract}
The response learning and associative hookup stages of paired-associate learning were studied in 8-year-old children as a function of intralist conceptual similarity. Response learning, as measured by response recall, was facilitated by the presence of similar items, while the associative stage, as measured by a matching test, was somewhat impeded by the use of category instances. These results are similar to those for young adults' learning, and indicate the utility of the stage-analysis model in the study of paired-associate learning by children.
\end{abstract}

Paired-associate learning has been conceptualized as consisting of two distinguishable stages, namely response learning and associative learning or hookup (e.g., Underwood, Runquist, \& Schulz, 1959). The use of a two-stage model has permitted investigators to identify the specific effects of certain variables on the two stages. For example, Underwood, Runquist, and Schulz (1959) found that high intralist similarity facilitated response recall while it had a deleterious effect on associative learning. The facilitation of response recall may be accounted for in terms of reducing S's information load, and the interference in the associative stage is probably related to S's difficulty in differentiating the stimulus items from one another. The present research extends this analysis to children's paired-associate learning.

The use of similar stimuli and responses is common in training children to learn to read, for example. Such popular television programs as The Electric Company and Sesame Street have employed such similarity manipulations in a modified paired-associate task. However, there has been little systematically collected experimental data on the effect of interpair stimulus and response similarity in children's paired-associate learning. The literature on the effects of similarity in children's learning has concerned primarily intrapair similarity or intertask similarity in transfer, often in an attempt to discover whether or not children use mediators in the same way as adults. Interpair similarity has been less 
Table 1

Average Number Correct During Acquisition and on the Recall and Matching Tests by Stages

\begin{tabular}{|c|c|c|c|c|c|}
\hline & & \multicolumn{2}{|c|}{ Stimulus Terms } & \multicolumn{2}{|c|}{ Response Terms } \\
\hline & & $\begin{array}{l}\text { Cate- } \\
\text { gory }\end{array}$ & $\begin{array}{l}\text { Unre- } \\
\text { lated }\end{array}$ & $\begin{array}{l}\text { Cate- } \\
\text { gory }\end{array}$ & $\begin{array}{l}\text { Unre- } \\
\text { lated }\end{array}$ \\
\hline Correct & $\begin{array}{l}\text { Trials 1-4 } \\
\text { Trials 5-8 }\end{array}$ & $\begin{array}{r}6.2 \\
18.1\end{array}$ & $\begin{array}{r}7.6 \\
20.6\end{array}$ & $\begin{array}{r}8.9 \\
22.9\end{array}$ & $\begin{array}{r}8.1 \\
21.3\end{array}$ \\
\hline Correct & $\begin{array}{l}\text { Trial } 4 \\
\text { Trial } 8\end{array}$ & $\begin{array}{l}2.4 \\
3.2\end{array}$ & $\begin{array}{l}2.4 \\
4.3\end{array}$ & $\begin{array}{l}3.2 \\
4.1\end{array}$ & $\begin{array}{l}2.2 \\
3.3\end{array}$ \\
\hline Recall & $\begin{array}{l}\text { Stage I } \\
\text { Stage II }\end{array}$ & $\begin{array}{l}4.4 \\
4.9\end{array}$ & $\begin{array}{l}4.7 \\
5.3\end{array}$ & $\begin{array}{l}6.5 \\
6.6\end{array}$ & $\begin{array}{l}5.4 \\
5.7\end{array}$ \\
\hline Matching & $\begin{array}{l}\text { Stage I } \\
\text { Stage II }\end{array}$ & $\begin{array}{l}2.8 \\
3.0\end{array}$ & $\begin{array}{l}3.1 \\
4.6\end{array}$ & $\begin{array}{l}3.3 \\
4.3\end{array}$ & $\begin{array}{l}2.4 \\
3.5\end{array}$ \\
\hline
\end{tabular}

frequently studied (e.g., Gaeth \& Allen, 1966; Girardeau, 1966), and then not within the context of the stage analysis noted above.

The two-stage analysis seems applicable to children's paired-associate learning (Goulet, 1968), although it has not always been utilized. For example, Lynch and Rohwer (1972) invoked the distinction between response learning and hookup in examining mnemonic elaboration effects, Kellas and Butterfield (1979) used this analysis to explain the effects of pronunciability and response familiarization, and this distinction has been invoked occasionally to explain paired-associate learning by retardates (e.g., Berry \& Baumeister, 1973). This distinction also seems implied in the studies of the effects of imagery in children's paired-associate learning (e.g., Yuille \& Pritchard, 1969), and Cole and Kanak (1972) found the distinction useful in the study of backward associations. However, no studies seem to exist which attempt to separate the effects of similarity in these two stages. To the extent that free learning is analogous to the response-learning stage (Ekstrand, 1966), some evidence indicates that the effects of associative and formal similarity on this stage are similar to those for adults (e.g., Heckelman \& Spear, 1967).

A study which considers similarity in both stages seems required, however, and the present experiment explored the effects of conceptual similarity in both the stimulus and response terms of children's paired-associate learning. At the same time, this experiment was intended to further explore the applicability of the stage-analysis model to paired-associate learning by children.

\section{METHOD}

\section{Materials}

Four basic types of lists of seven paired associates each were formed. The stimuli were printed on one side of $4 \times 5 \frac{1}{2}$ in. gray cards, while on the reverse side both the stimulus and response were printed.

In the first type of list, List NC, the stimuli were low-meaningful low-similarity two-digit numbers selected from the lower $40 \%$ of the Battig and Spera (1962) norms, and all seven responses were $\mathrm{A}$ or AA frequency words selected from one category in the Battig and Montague (1969) norms. The second type of list, List CN, was identical to the NC list except that now the categorically related words served as stimuli and the numbers were responses. For both of these lists, three different forms were used, with each involving a different category to avoid arbitrary results.

The third type of list, List NU, used the same numbers as the NC list as stimuli, but now the responses were unrelated words. The fourth list, List UN, simply reversed the function of the materials in the NU list. As before, three forms were used for further generality in the results.

\section{Procedure}

Fifteen Ss were individually assigned to each of the four groups defined by the list types on the basis of a prearranged random schedule. Prior to the test list, two sample paired-associate cards were presented to the $S$ with paired-associate instructions. The sample pairs conformed to the list type which $\mathrm{S}$ would be tested on later, i.e., NC, CN, NU, or UN. Two correct trials were required on the sample pairs before the test list was presented.

The anticipation method was used throughout, with a $4: 4-\mathrm{sec}$ rate of presentation and an intertrial interval of $10 \mathrm{sec}$. The cards were randomly mixed between list presentations to reduce serial learning effects. Prior to the first test trial, Ss were given one familiarization trial for the test pairs.

Following the fourth test trial, paired-associate acquisition was interrupted and Ss were asked to verbally free recall the responses without the presentation of the stimuli; guessing was encouraged. Following this recall test, a matching test was given. Stimulus cards similar to those used in acquisition were placed before the $S$ along with a stack of cards with the responses on them, and the $S$ was asked to match the pairs. Following these two tests, paired-associate acquisition proceeded using the initial anticipation format. At the end of four more trials, the response recall and associative matching measures were again taken to complete the experimental session.

\section{Subjects}

The Ss were 60 third-grade students from a parochial school in Chicago. They had a mean age of 8 years, 5 months. Approximately an equal number of males and females were assigned to each of the four groups.

\section{RESULTS}

\section{Acquisition Performance}

Table 1 summarizes the results of paired-associate acquisition, response recall, and associative matching, by stages. The acquisition results were analyzed as a 2 by 2 by 2 factorial design, with the two stages (Trials 1-4, Trials 5-8) as the first factor, similarity (category, unrelated) as the second factor, and the locus of the similarity manipulation (stimulus, response) as the third factor. Considering the total number of correct anticipations as the data in this analysis, stages was the only significant effect, $F(1,56)=286.39, p<.001$.

Considering the number correct on Trial 4 only and Trial 8 only, i.e., the trials just before each of the interpolated tests, the stages main effect was also present, $F(1,56)=42.51, p<.001$, with marginal interactions of Stages by Similarity, $F(1,56)=3.47$, $p<.10$, and Similarity by Locus, $F(1,56)=2.98$, $\mathrm{p}<.10$. The former interaction suggested that similarity effects were most apparent on Trial 8. The latter 
interaction suggested that high similarity was detrimental when located in the stimulus terms but helpful when in the response terms. While this interaction is suggestive of the effects expected by the two-stage conceptualization of paired-associate learning, the magnitude of the effect seems limited by the combined positive and negative effects of similarity on overall acquisition. The other measures were specifically collected to separate these effects.

\section{Response Recall}

The data from the two response recall tests were analyzed in a similar layout. The stages main effect was again significant, $F(1,56)=12.68, \mathrm{p}<.001$, but there were no interactions with stages, Fs $<2.20$. While there was no main effect of similarity for response recall, $F(1,56)=1.31$, there was a significant main effect of locus, $\mathrm{F}(1,56)=20.95, \mathrm{p}<.001$, and the Similarity by Locus interaction was significant, $F(1,56)=6.47$, $\mathrm{p}<.025$. Individual comparisons of the means of this interaction indicated that an increment in stimulus similarity had a nonsignificant inhibiting effect upon response recall, List $\mathrm{CN}$ vs List $\mathrm{UN}$, but an increment in response similarity led to significantly more response recall $(\mathrm{p}<.05)$, List $\mathrm{NC}$ vs List NU, as would be expected $r y$ the stage analysis discussed above. No other effects reached significance, Fs $<1$.

\section{Matching}

The same analysis was performed on the matching data collected after the fourth and eighth test trials. The stages main effect was again significant, $F(1,56)=15.34$, $\mathrm{p}<.001$, but it did not interact with either of the other factors, Fs $<2.37$. The Similarity by Locus interaction was again significant, $F(1,56)=4.08, p<.05$, this time indicating that high similarity stimulus terms did yield less matching, List $\mathrm{CN}$ vs List $\mathrm{UN}$, while high similarity response terms facilitated matching, List NC vs List NU. Neither of these trends quite reached significance in individual comparisons, however. No other effects reached significance, Fs $<1.25$.

\section{DISCUSSION}

Overall paired-associate acquisition revealed little effect due to similarity manipulations, presumably because high similarity simultaneously impedes the associative stage while facilitating the response learning stage. Restricting the analysis to the trial just before the first interpolated tests and the trial just before the final tests, however, there was some indication even in overall paired-associate performance that the two-stage conceptualization was appropriate. That is, high-stimulus similarity retarded acquisition while high response similarity facilitated acquisition.

Strengthening this interpretation were the results from the interpolated recall and matching tests. According to the two-stage analysis of paired-associate learning, high-response similarity should aid in response learning, since in the present case the category labels provided a common code for the response items. The response recall test after Trials 4 and 8 was intended to test this prediction. This expectation was borne out by the significant Similarity by Locus interaction for response recall, as similar responses produced better recall.

The two-stage analysis further predicts that high stimulus similarity would retard the associative hookup stage, and this was tested by taking the matching test after Trials 4 and 8 . There was again the required Similarity by Locus interaction, though in this case the high-and low-stimulus similarity groups did not differ individually. The basis for the expected interference here is that the similar stimuli evoke a common labeling response, even though the overt responses to be made are different for each instance. Perhaps the category instances here did not evoke the common label quite as reliably as is the case for adults, thus accounting for the slightly reduced effect of stimulus similarity on matching, i.e., the stimuli are higher in encoding variability for children (cf. Martin, 1968). However, the category label seems to have been strong enough to produce facilitation in response recall when the instances served as response terms, so it seems likely that some methodological factor, e.g., list size or number of categories per list, is the cause.

In conclusion, the two-stage analysis clearly seems applicable to children's paired-associate learning. Furthermore, interstimulus and interresponse similarity seem to be important factors in children's learning. That these two cases can be identified as having opposed effects on the two stages in laboratory learning provides some useful structure for expectations about the manipulation of similarity in more applied training situations.

\section{REFERENCES}

Battig, W. F., \& Montague, W. E. Category norms for verbal items in 56 categories: A replication and extension of the Connecticut category norms. Journal of Experimental Connecticut category norms. Jourt
Psychology, 1969, 80, (No. 3, Pt. 2).

Battig, W. F., \& Spera, A. J. Rated association values of numbers from 0-100. Journal of Verbal Learning \& Verbal Behavior, 1962, 1, 200-202.

Berry, F. M., \& Baumeister, A. A. Paired-associate learning by normal children and retardates with relevant redundant compound stimuli. Journal of Experimental Child Psychology, $1973,15,63-76$.

Cole, L. E., \& Kanak, N. J. Paired-associate learning and bidirectional associative recall in first, third, fifth, and seventh graders. Journal of Experimental Child Psychology, 1972, 13, 128-137.

Ekstrand, B. R. A note on measuring response learning during paired-associate learning. Journal of Verbal Learning \& Verbal Behavior, 1966, 5, 344-347.

Gaeth, J. H., \& Allen, D. V. Effect of similarity upon learning in children. Journal of Experimental Child Psychology, 1966, 4, 381-390.

Girardeau, F. L. Paired-associate learning: Similarity among stimulus terms. Psychonomic Science, 1966, 4, 423-424.

Goulet, L. R. Verbal learning in children: Implications for developmental research. Psychological Bulletin, 1968, 69, developm

Heckelman, S. B., \& Spear, N. E. Effect of interitem similarity on free learning by children. Journal of Verbal Learning \& Verbal Behavior, 1967, 6, 448-450.

Kellas, G., \& Butterfield, E. C. The interaction of pronunciability and response pretraining on the paired-associate performance of third-grade children. Journal of Experimental Child Psychology, 1970, 9, 265-271.

Lynch, S., \& Rohwer, W. D. Grade interaction with words and pictures in a paired-associate task: A proposed explanation. Journal of Experimental Child Psychology, 1972, 13, 413-421.

Martin, E. Stimulus meaningfulness and paired-associate transfer: An encoding variability hypothesis. Psychological Review, $1968,75,421-441$.

Underwood, B. J., Runquist, W. N., \& Schulz, R. W. Response learning in paired-associate lists as a function of intralist similarity. Journal of Experimental Psychology, 1959, 58, 70-78.

Yuille, J. C., \& Pritchard, S. Noun concreteness and verbal facilitation as factors in imaginal mediation and PA learning in children. Journal of Experimental Child Psychology, 1969, 7, 459-466.

(Received for publication January 21, 1974.) 